\title{
Extracorporeal techniques for the treatment of critically ill patients with sepsis beyond conventional blood purification therapy: the promises and the pitfalls
}

\author{
Ghada Ankawi ${ }^{1,2^{*}}$ (D) Mauro Neri ${ }^{2,3}$, Jingxiao Zhang ${ }^{2,4}$, Andrea Breglia ${ }^{2,5}$, Zaccaria Ricci ${ }^{6}$ and Claudio Ronco ${ }^{2,3}$
}

\begin{abstract}
Sepsis is one of the leading causes of morbidity and mortality worldwide. It is characterized by a dysregulated immune response to infections that results in life-threatening organ dysfunction and even death. Bacterial cell wall components (endotoxin or lipopolysaccharide), known as pathogen-associated molecular patterns (PAMPs), as well as damage-associated molecular patterns (DAMPs) released by host injured cells, are well-recognized triggers resulting in the elevation of both pro-inflammatory and anti-inflammatory cytokines. Understanding this complex pathophysiology has led to the development of therapeutic strategies aimed at restoring a balanced immune response by eliminating/deactivating these inflammatory mediators. Different extracorporeal techniques have been studied in recent years in the hope of maximizing the effect of renal replacement therapy in modulating the exaggerated host inflammatory response, including the use of high volume hemofiltration (HVHF), high cut-off (HCO) membranes, adsorption alone, and coupled plasma filtration adsorption (CPFA). These strategies are not widely utilized in practice, depending on resources and local expertise. The literature examining their use in septic patients is growing, but the evidence to support their use at this stage is considered of low level. Our aim is to provide a comprehensive overview of the technical aspects, clinical applications, and associated side effects of these techniques.
\end{abstract}

Keywords: Sepsis, Acute kidney injury, Renal replacement therapy, Extracorporeal technique, High volume hemofiltration, High cut-off membranes, Adsorption, Coupled plasma filtration adsorption

\section{Background}

The battle against sepsis is longstanding. Healthcare professionals continue to search for treatment modalities to improve the outcomes of patients suffering from this syndrome. The definition of sepsis has evolved over the years. An older definition was based on meeting two systemic inflammatory response syndrome (SIRS) criteria due to a presumed infection. In 2016, SIRS was replaced with the quick Sequential Organ Failure Assessment

\footnotetext{
* Correspondence: ghadaankawi@gmail.com

${ }^{1}$ Department of Internal Medicine and Nephrology, King Abdulaziz University, Jeddah, Saudi Arabia

${ }^{2}$ International Renal Research Institute of Vicenza (IRRIV), Vicenza, Italy

Full list of author information is available at the end of the article
}

score (qSOFA), which consists of two of the following: increased breathing rate, change in level of consciousness, and low blood pressure. This was generated by national societies, including the Society of Critical Care Medicine (SCCM) and the European Society of Intensive Care Medicine (ESICM) [1, 2].

Sepsis is characterized by a dysregulated immune response to infections that results in life-threatening organ dysfunction. The exaggerated immune response beyond the infection site is multifactorial. Bacterial cell wall components (endotoxin or lipopolysaccharide (LPS)), known as pathogen-associated molecular patterns (PAMPs), and damage-associated molecular patterns (DAMPs) released by injured host cells play a 
major role in mounting this response with the subsequent release of both pro-inflammatory/anti-inflammatory cytokines. LPS has been found to cause a dose-dependent elevation in cytokines when injected systemically $[3,4]$. Understanding of this complex mechanism has led to the development of treatment strategies aimed at restoring a balanced immune response by eliminating/deactivating these inflammatory mediators. Conventional therapy of sepsis typically starts with resuscitative measures; however, the only definitive therapy is adequate antibiotics and source control in surgical cases of sepsis [5]. Renal replacement therapy (RRT) is recommended in septic patients who develop acute kidney injury (AKI). Studies have shown no difference in outcomes comparing continuous RRT (CRRT) with intermittent RRT [6], and CRRT is generally reserved for hemodynamically unstable patients in need of fluid balance control [5]. Another application for RRT (hemofiltration in particular) is the extracorporeal removal of inflammatory mediators. In earlier studies, RRT alone was not sufficient to decrease serum cytokine levels [7], which led to the development of more effective extracorporeal techniques supported by controversial evidence at this stage. High volume hemofiltration (HVHF) or very high volume hemofiltration (VHVHF), high cut-off (HCO) membranes, adsorption alone, and coupled plasma filtration adsorption (CPFA) are among the major evolving strategies. These techniques are variably applied in different centers, depending on different clinician skills, equipment availability, and patient cases (i.e., surgical vs medical). In this review, we summarize the basic principles of these extracorporeal techniques. We also highlight the risks that should be carefully balanced against the potential benefits, given the low level of evidence supporting their effectiveness.
High volume hemofiltration and very high volume hemofiltration

\section{Terminology}

The definition of HVHF remains controversial. Based on a consensus conference on the nomenclature of RRT held in Vicenza, Italy [8], HVHF was defined as continuous treatment with a convective target dose (prescribed) greater than $35 \mathrm{ml} / \mathrm{kg} / \mathrm{h}$. Doses greater than $45 \mathrm{ml} / \mathrm{kg} / \mathrm{h}$ were defined as VHVHF. As a technique, it has been utilized for immunomodulation in the context of both AKI $[9,10]$ and sepsis. Our review will focus on the role of HVHF in sepsis. Although HVHF per se should be exclusively conducted by convective modalities, as this is the main mechanism by which inflammatory mediators are removed, some authors have delivered it combined with different approaches [11]. We will review HVHF and VHVHF simultaneously given the lack of standardized definitions, including the description of an additional complementary (diffusive) dose. HVHF and VHVHF circuits are shown in Fig. 1.

\section{Technical aspects}

HVHF and VHVHF are easily implemented in centers capable of performing conventional CRRT, as no additional component to the usual circuit is needed.

- Type of dialyzer: high flux dialyzer (Kuf $>25 \mathrm{ml} / \mathrm{h} / \mathrm{mmHg} / \mathrm{m}^{2}$ ).

- Blood flow rate (Qb): since HVHF and VHVHF require high ultrafiltration flows, required $\mathrm{Qb}$ typically must guarantee no excessive filtration fraction values (not $>25-30 \%$ ).

- Dose: convective, greater than $35-45 \mathrm{ml} / \mathrm{kg} / \mathrm{h}$. The overall dose can be higher $(50-70 \mathrm{ml} / \mathrm{kg} / \mathrm{h})$ due to a complementary diffusive component (continuous veno-venous hemodiafiltration (CVVHDF)).

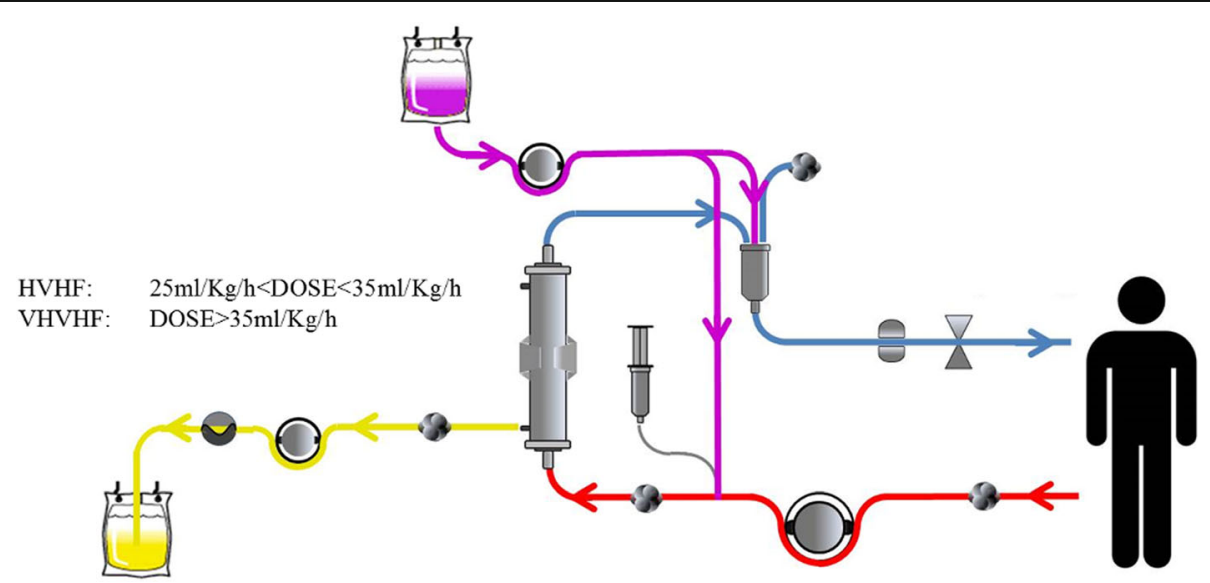

Fig. 1 Circuit components in high volume hemofiltration (HVHF) and very high volume hemofiltration (VHVHF). Arterial line (red), ultrafiltrate (yellow), replacement fluid (purple), and venous line (b/ue) 
- Replacement fluid (Qr): in pre- and/or post-dilution mode. For a given target dose, it is necessary to consider that the pre-dilution Qr must be higher than the post-dilution.

- Duration: tailored to the patient's condition.

- Anticoagulation: heparin or citrate.

\section{The evidence}

The evidence for the effectiveness of high volume hemofiltration is presented in Table 1 . The body of evidence is derived largely from small observational studies/randomized controlled trials (RCTs) [12-16]. The largest and only multi-center RCT to date is the IVOIRE trial [17]. It should be noted that different protocols were used with doses ranging from 40 to $70 \mathrm{ml} / \mathrm{kg} / \mathrm{h}$. A few studies have also utilized so-called pulse high volume hemofiltration (PHVHF), where intermittent very highvolume treatment is followed by conventional renal-dose hemofiltration [18-20]. Additionally, in a large Chinese cohort, higher doses of $50 \mathrm{ml} / \mathrm{kg} / \mathrm{h}$ were compared to $85 \mathrm{ml} / \mathrm{kg} / \mathrm{h}$ [21]. The results overall were inconsistent. Earlier observational studies have suggested a mortality benefit and improvement of hemodynamics, while later studies (IVOIRE trial in particular) did not confirm these findings. A recent systematic review [22] showed a pooled estimate of mortality risk ratio (RR) of 0.89 (95\% CI 0.60 1.32; two trials; $N=156$ ), and the strength of evidence was considered low. This finding was comparable to earlier meta-analyses by Clark et al. [23] and Lehner et al. [24]. The former showed the pooled odds ratio for 28-day mortality for HVHF compared with a standard volume hemofiltration (SVHF) of 0.76 (95\% CI 0.45-1.29; $p=0.31$ ), and the latter also demonstrated a lack of effect on mortality, with HFHV (OR 0.85; 95\% CI 0.50-1.45; four trials; $N=473$ ), PHVHF (OR 0.62; 95\% CI 0.22-1.74; three trials; $N=85$ ), or both combined (OR $0.85 ; 95 \%$ CI $0.60-1.22$; seven trials; $N=558$ ). It should be noted that some studies included by Lehner et al. [24] utilized hemodialysis and were not conducted exclusively in the context of sepsis. Furthermore, in a recent RCT involving a subpopulation of patients with septic shock secondary to burns, HVHF (versus standard therapy) was found to be effective in improving organ function but not survival [25]. To conclude, despite the promising results of earlier studies, HVHF seems to have no significant impact on short-term mortality, improvement in hemodynamics, or reduction in intensive care unit (ICU) or hospital length-of-stay (LOS).

HVHF is feasible and readily available in centers capable of performing conventional CRRT. The evidence to support its effectiveness in improving patient hemodynamics and mortality (although promising in earlier studies) is insufficient.

\section{High cut-off membranes}

Terminology

High cut-off $(\mathrm{HCO})$ membranes are characterized by a large pore size (average pore diameter $(20 \mathrm{~nm})$ compared with the standard high-flux membrane $(10 \mathrm{~nm})$. Our focus will be the use of HCO membranes in CRRT in the context of sepsis.

A HCO membrane circuit is shown in Fig. 2.

\section{Technical aspects}

HCO membrane use is similar to the standard RRT prescription, including the choice of anticoagulation. The prescribed dose is typically in the range from 25 to $40 \mathrm{ml} / \mathrm{kg} / \mathrm{h}$, as recommended by Kidney Disease Improving Global Outcomes (KDIGO) guidelines [26]. Convective modalities would maximize the $\mathrm{HCO}$ membrane ability to remove pro/anti-inflammatory mediators [27], but the excessive albumin loss commonly observed with the use of such membranes dictates the utilization of only diffusive modalities.

The use of $\mathrm{HCO}$ membranes is not limited to sepsis, which is the focus of our review. High-cut-off hemodialysis, for instance, is also used in the management of AKI in patients with rhabdomyolysis and multiple myeloma.

\section{The evidence}

The evidence for the effectiveness of $\mathrm{HCO}$ membranes is presented in Table 2. The body of evidence comes from small RCTs and observational studies [28-34]. Overall, the studies are suggestive of a decrease in inflammatory cytokines and improvement of hemodynamics, along with an improvement in ICU patient severity of illness scores as reported by Morgera et al. [27-30]. One study comparing continuous veno-venous hemodialysis with $\mathrm{HCO}$ membranes (HCO-CVVHD; at a dose of $35 \mathrm{ml} / \mathrm{kg} / \mathrm{h}$ ) vs CVVHDF (at a dose of $45 \mathrm{ml} / \mathrm{kg} / \mathrm{h}$ ) showed an ICU mortality benefit (37.5 and $87.5 \%$ for HCO-CVVHD and CVVHDF groups, respectively $(p=0.03))$, but no significant difference was found in ICU-LOS and in-hospital mortality [32]. Furthermore, the High Cut-Off Sepsis study (HICOSS) comparing conventional and $\mathrm{HCO}$ membranes was stopped prematurely after enrolment of 81 patients due to a lack of 28-day mortality benefit ( $\mathrm{HCO}(31 \%)$ vs conventional (33\%)) and lack of a difference in vasopressor requirement or ICU-LOS [35].

Based on the reviewed literature, there is no evidence to support the use of HCO hemofiltration in sepsis. Lack of standardized definitions of dialysis membranes [36] has contributed to the paucity of high-quality data supporting their use. 


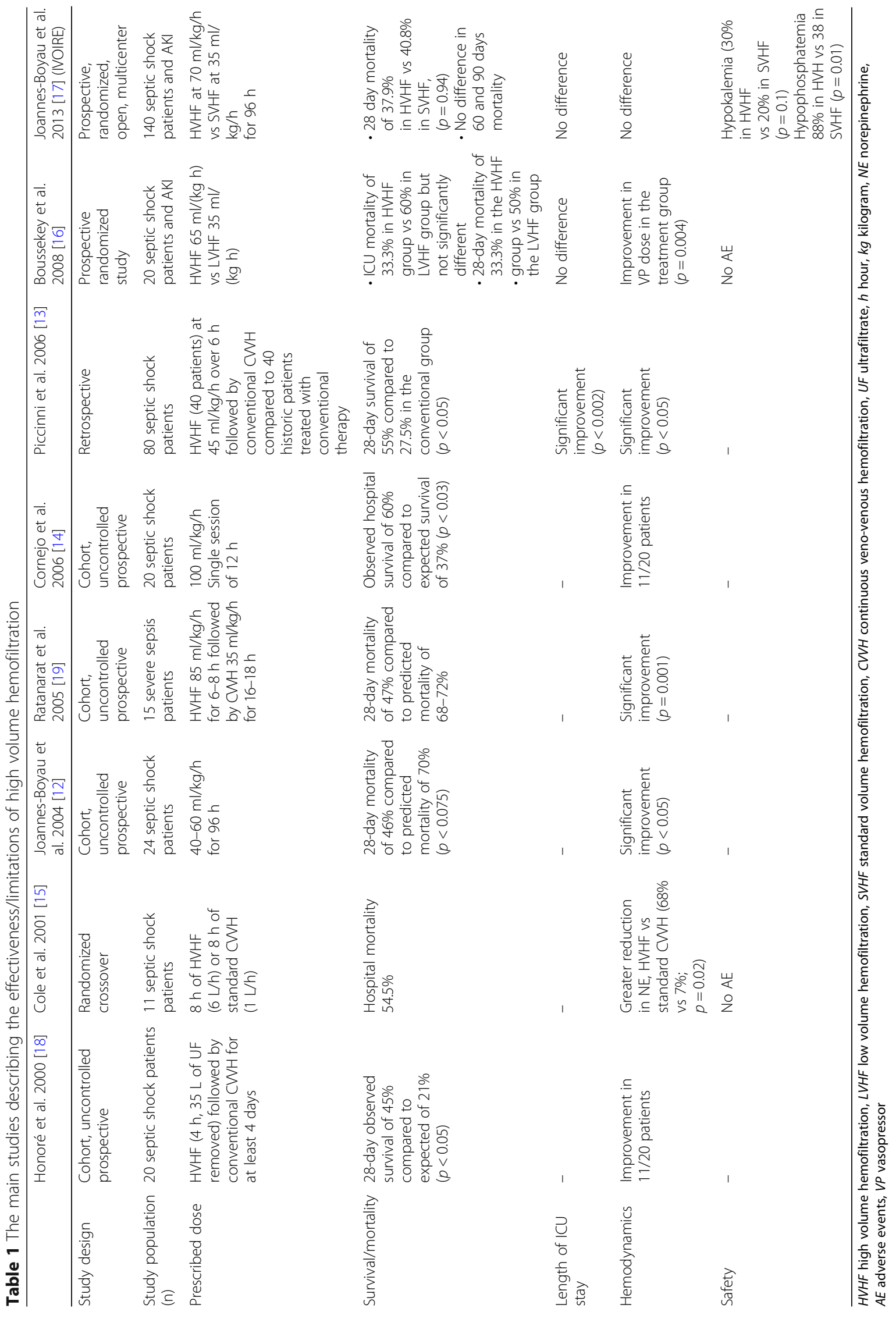




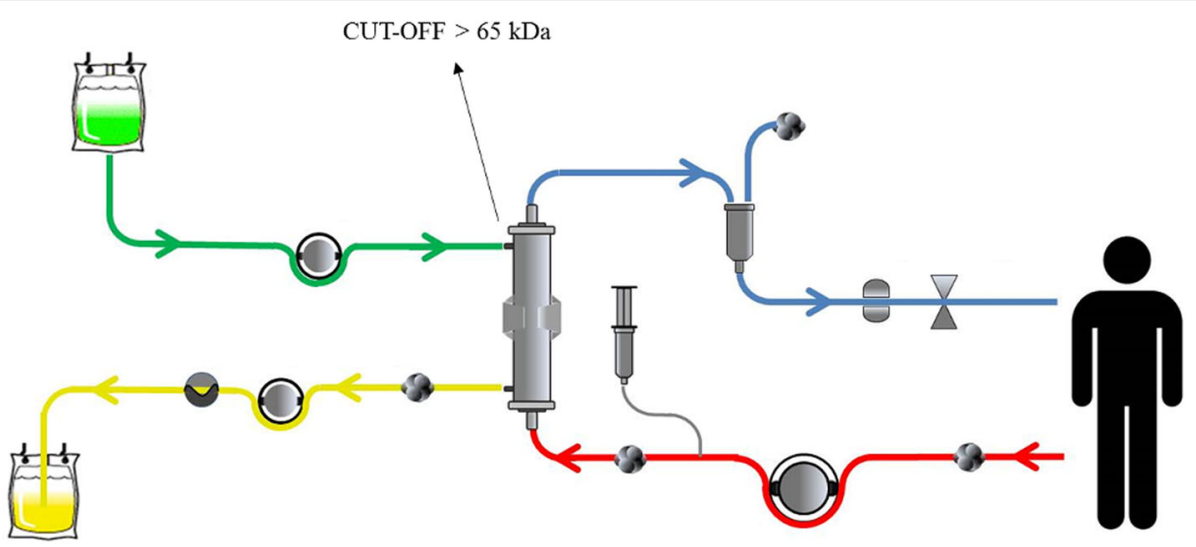

Fig. 2 Circuit components using high cut-off membranes. Arterial line (red), ultrafiltrate (yellow), dialysate (green), and venous line (blue)

\section{Adsorption}

\section{Terminology}

Adsorption is performed in the form of hemoperfusion (HP), plasma perfusion, or coupled plasma filtration adsorption (CPFA) (detailed in the "Coupled plasma filtration adsorption (CPFA)" section). HP involves passage of blood through a hemofilter where mediators are adsorbed to the membrane surface or through a sorbent-containing cartridge. We will focus on the use of adsorption in sepsis; however, it has also been studied in the context of cardiopulmonary bypass surgery and other conditions. In sepsis, it is generally advocated for treating patients with suspected Gram-negative sepsis or septic shock.

Circuit components in adsorption are shown in Fig. 3.

\section{Technical aspects}

Adsorption can be used in isolation or in combination with HD or continuous veno-venous hemofiltration $(\mathrm{CVVH})$. More than one session is often required to overcome the possible rebound. Prescription (including the duration of therapy) depends on the adsorption cartridge used (summarized in Table 3) and should always be guided by the user manual. This is a rapidly evolving area and we will focus on the widely used cartridges.

\section{The evidence}

The evidence for adsorption is presented in Tables 4, 5, 6, and 7).

Polymyxin B-immobilized fiber column The body of evidence for the polymyxin B-immobilized fiber column (PMX; Toraymyxin) comes from three major RCTs [37-39], data from two registries [40-42], and four meta-analyses that included the earlier smaller RCTs conducted in Japan [43-46]. To date, the evidence remains largely mixed. Data from the EUPHAS trial [38] suggest a mortality benefit (28-day mortality, $32 \%$ in the treatment group vs $53 \%$ in the control group; adjusted HR 0.36, 95\% CI 0.16-0.80) and a hemodynamic benefit, but no effect on ICU-LOS (20.3 days in PMX group (95\% CI 15.0-25.5 days) vs 18.3 days (95\% CI $8.8-$ 27.8 days) in the control group; $p=0.72$ ). In contrast, data from the ABDO-MIX trial [39] suggest no mortality benefit (28-day mortality $27.7 \%$ in the treatment group vs $19.5 \%$ in the control group; $p=0.14$; OR $1.5872 ; 95 \% \mathrm{CI}$ $0.8583-2.935)$ and no impact on hemodynamics or ICU-LOS (11 days in the PMX-HP vs 10 days in the control group; $p=0.49$ ). However, cartridge clotting and treatment failure rates were high in this trial (two PMX sessions were completed in only $69.8 \%$ of patients), which may partially explain the findings. Similarly, two retrospective studies reported by Iwagami et al. [40, 41] showed conflicting results. The first showed no significant difference in 28 -day mortality $(17.1 \%$ in the treatment group compared with $16.3 \%$ in the control group; $p=0.696)$. In contrast, the second study showed 28-day mortality benefit $(40.2 \%$ in the PMX group vs $46.8 \%$ in the control group; $p=0.003)$. A recent meta-analysis [47] (seven RCTs, 841 patients) suggested a reduction of mortality (RR $0.65 ; 95 \%$ CI $0.47-0.89 ; p=0.007$ ), which was similar to the results of the previous meta-analyses conducted by Cruz et al. [44] (RR 0.50; 95\% CI 0.37-0.68), Qiu et al. [45] (RR 0.24; 95\% CI 0.16-0.38), and Zhou et al. [46] (RR 0.57; 95\% CI 0.450.72). However, it was considered to be low-quality evidence due to the serious risk of bias. All the trials were small, open-label, and conducted in single centers in Japan. Additionally, most of the trials involved a surgical population, and thus the results may need to be interpreted with caution when applying the results to medical ICU patients.

The EUPHRATES trial conducted in North America (NCT01046669) has recently completed enrolment, and the results will soon be officially available. Preliminary reports, however, suggest that less than a $5 \%$ mortality difference was recognized in the "per 


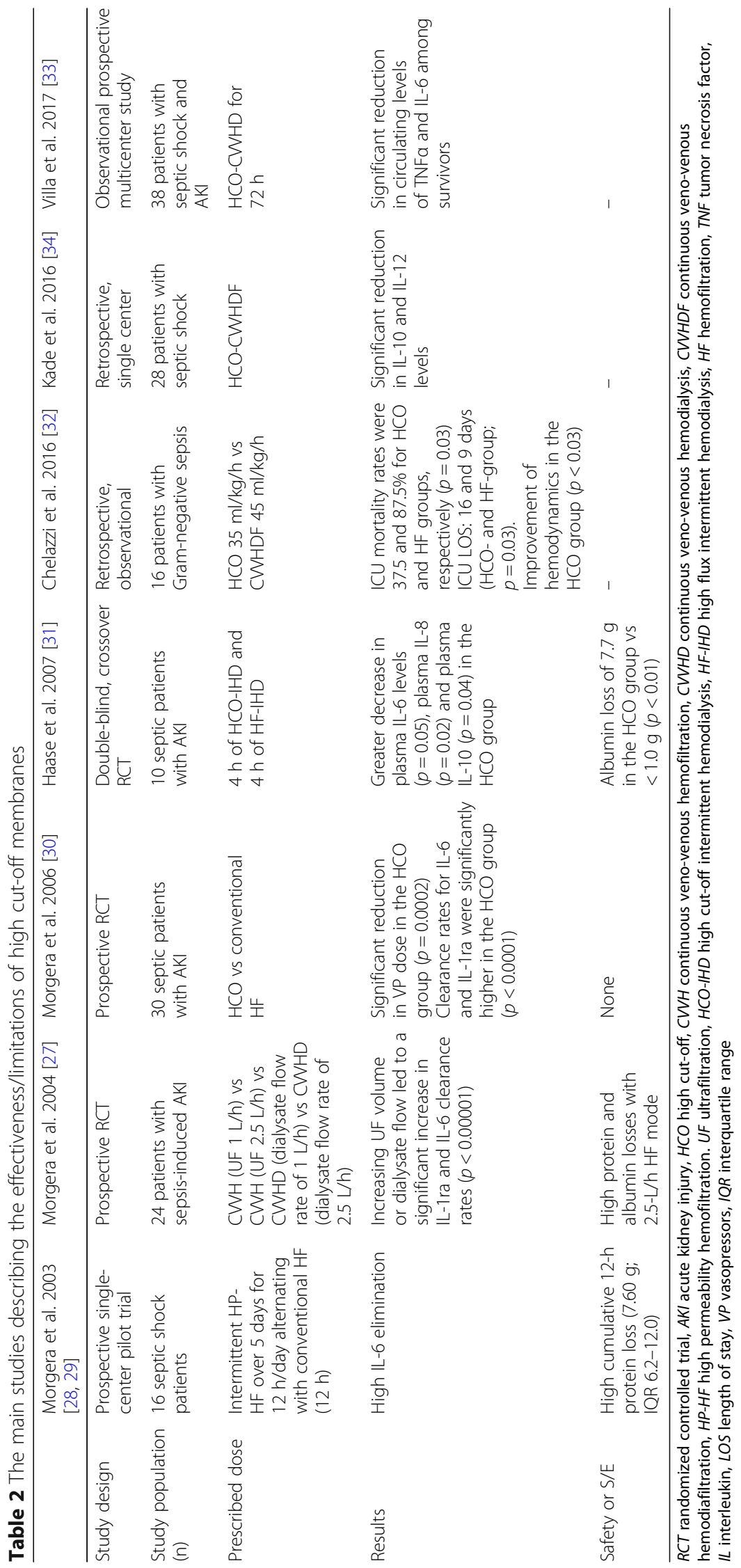




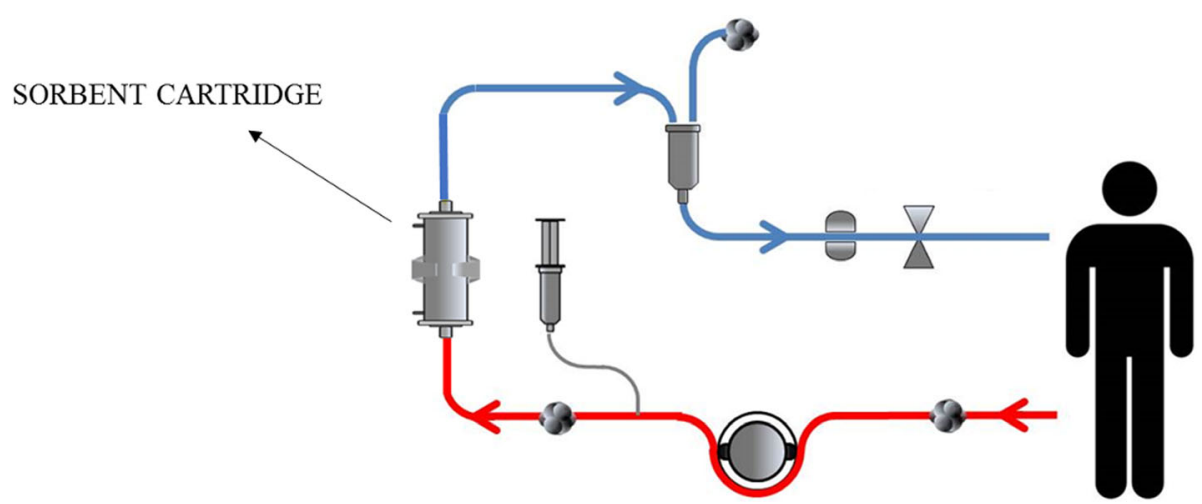

Fig. 3 Circuit components in adsorption. Arterial line (red) and venous line (b/ue)

protocol population" ( $N=244,31.9$ vs $36.9 \%)$ and that the decrease was not statistically significant [48]. Further analysis of potential benefits in subgroups of patients is ongoing. Of note, PMX use was found to be largely safe. Thrombocytopenia and leukopenia are common but generally not clinically significant.

Cytosorb The evidence for cytosorb (CS) is limited to case reports/series and a few RCTs, but it is growing. Observational data $[49,50]$ suggest improvement in hemodynamics and a trend towards decreased mortality. In addition, a reduction of interleukin (IL)-6 levels has been observed, consistent with the findings of Kellum et al. examining the effect of CS on IL-6/other cytokines in brain-dead potential donors [47]. Two RCTs [51, 52] have also shown a reduction of IL-6 levels, but this result was not associated with an improvement in mortality, although the studies were not powered to evaluate mortality, and in the latter study [52] the treatment group had more severe disease compared with the controls. A clinical registry on the use of CS involving 22 countries has been developed, and according to its most recent report, the use of CS in 135 septic patients was not associated with side effects. The observed mortality was $65 \%$ compared with a predicted risk of death of $78 \%$ based on the Acute Physiology and Chronic Health Evaluation II (APACHE II) score. A marked reduction of IL-6 levels was also observed [53]. One drawback is that CS does not capture endotoxins and IL-10. Albeit in an in vitro study testing the removal of a broad spectrum of toxic PAMPS and DAMPS [54], except for the tumor necrosis factor (TNF)- $\alpha$ trimer, hemadsorption using CS reduced the levels of a broad spectrum of cytokines, DAMPS, PAMPS, and mycotoxins by $>50 \%$. Because of the unspecific mediator-elimination properties of CS, it has been widely studied in the context of cardiac surgery. In a recent report by Bernardi et al. [55], CS was applied to elective cardiopulmonary bypass surgery patients. This was not associated with reduction in IL-6 level or improved clinical outcomes. This finding may partially be explained by the finding that cytokine levels in this patient population were not as high as in septic patients. Another caveat is the treatment duration (average $191 \pm 56$ min compared with treatment lasting for up to 7 days in other studies). This emphasizes the effect of both the initial level of cytokines and the treatment frequency/duration on the extent of cytokine reduction.

HA-330 In the context of sepsis, two small RCTs described effectiveness of HA-330 in decreasing inflammatory mediators, along with an improvement in hemodynamics, mortality, and ICU-LOS $[56,57]$. One of the trials was conducted in septic patients with acute lung injury, in which there was marked improvement in respiratory parameters in the HP group [57].

Modified AN69 (Oxiris) The evidence supporting the use of modified AN69 is limited to case series $[58,59]$. In the study reported by Shum et al. [59], oXiris ${ }^{\circ}-\mathrm{CVVH}$ was delivered to six patients with septic AKI, and the results were compared to 24 severity-matched historical controls undergoing standard therapy. The results demonstrated that the SOFA score was reduced after 48-h $\mathrm{CVVH}$ from the value at ICU admission by $38 \%$ in the oXiris ${ }^{\circ}$ group, while it was increased by $3 \%$ in the control group. No significant difference was observed in ICU and in-hospital mortality between the two groups. More studies investigating its effectiveness are ongoing (NCT01948778, NCT02600312).

LPS adsorbers (Alteco) Evidence for LPS adsorbers was obtained from case reports/series [60-62] that showed a decrease in endotoxin level as well as improvement in patient hemodynamics with no significant side effects. A feasibility study (The ASSET trial) was unfortunately 


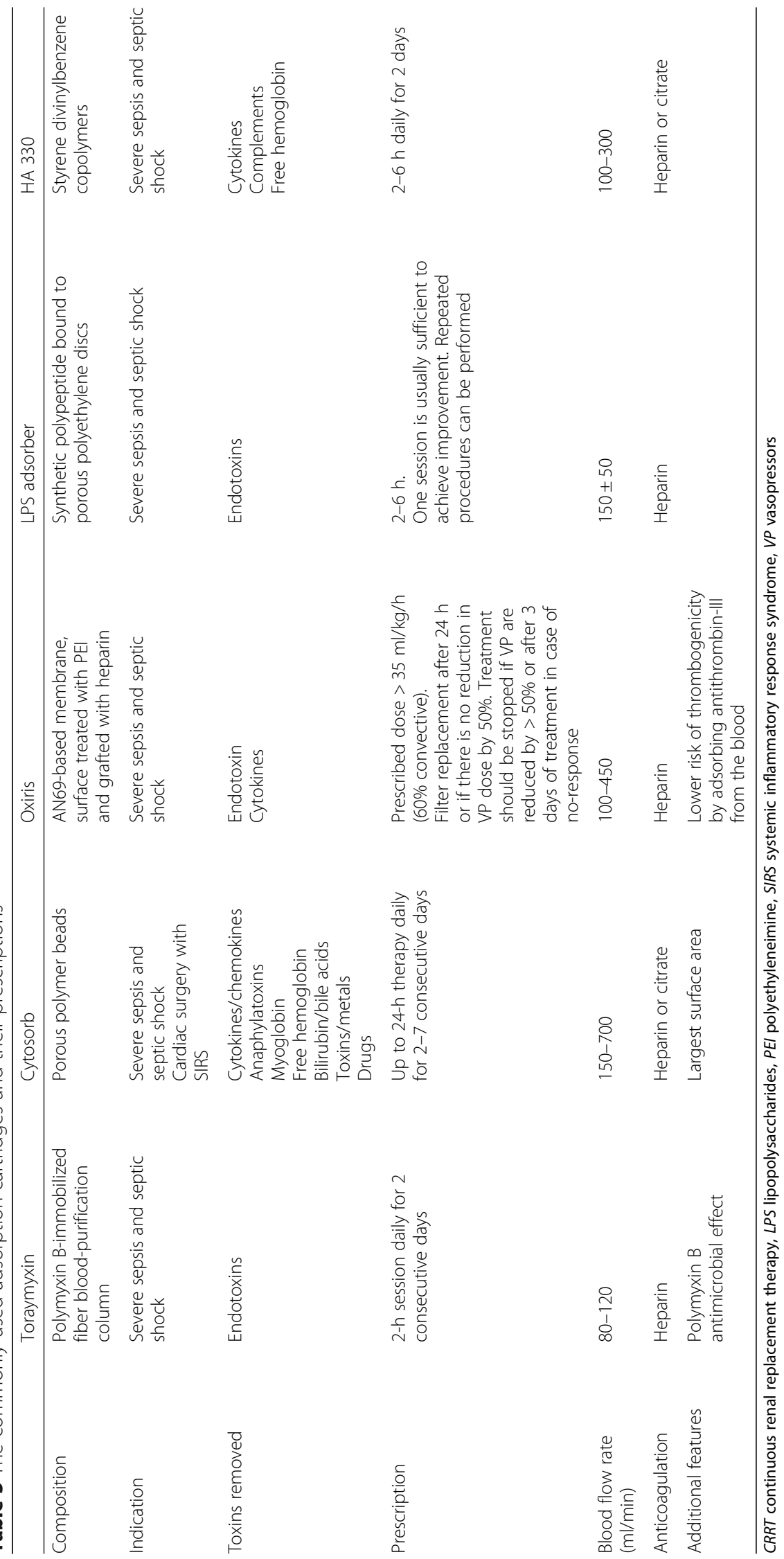




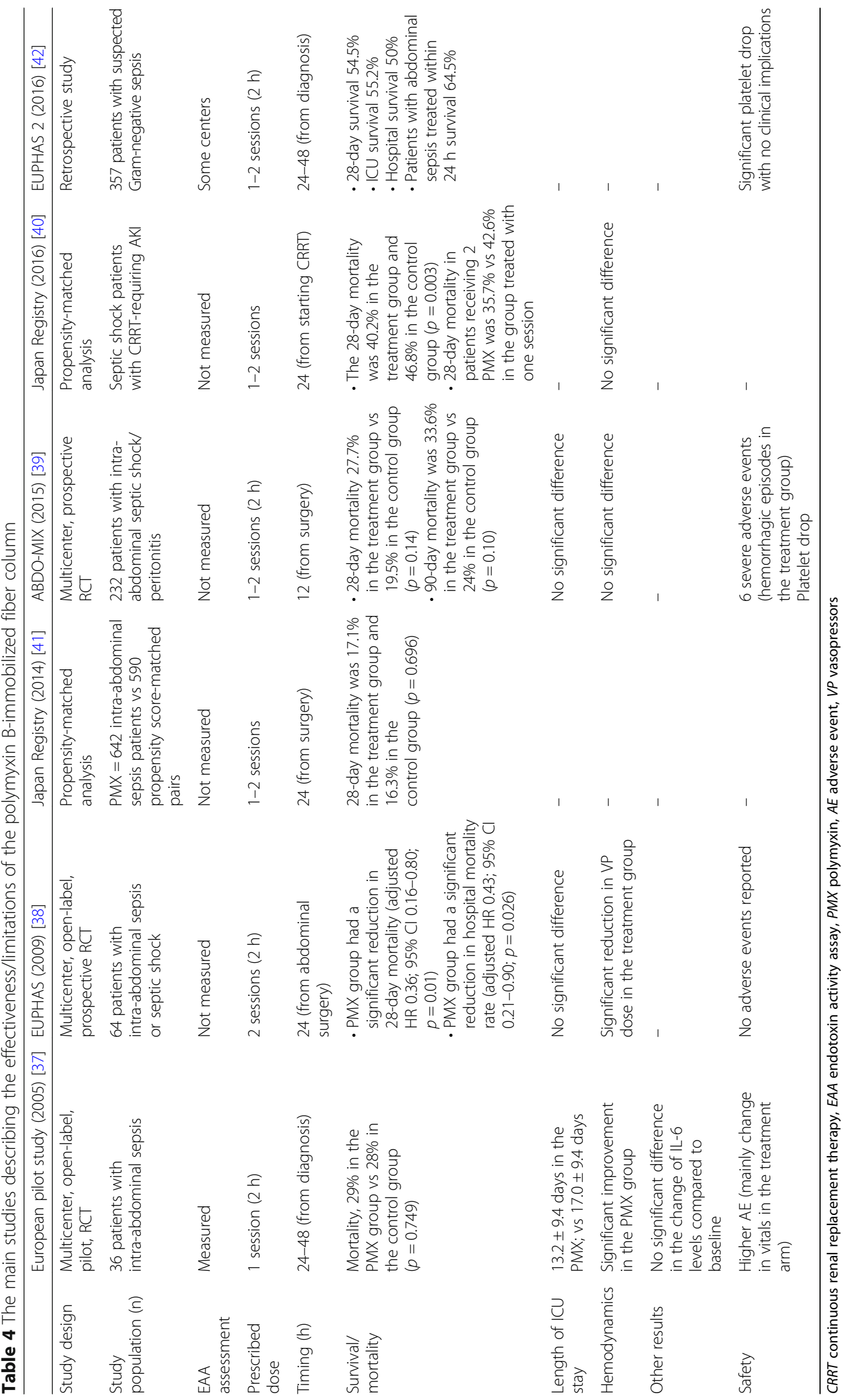




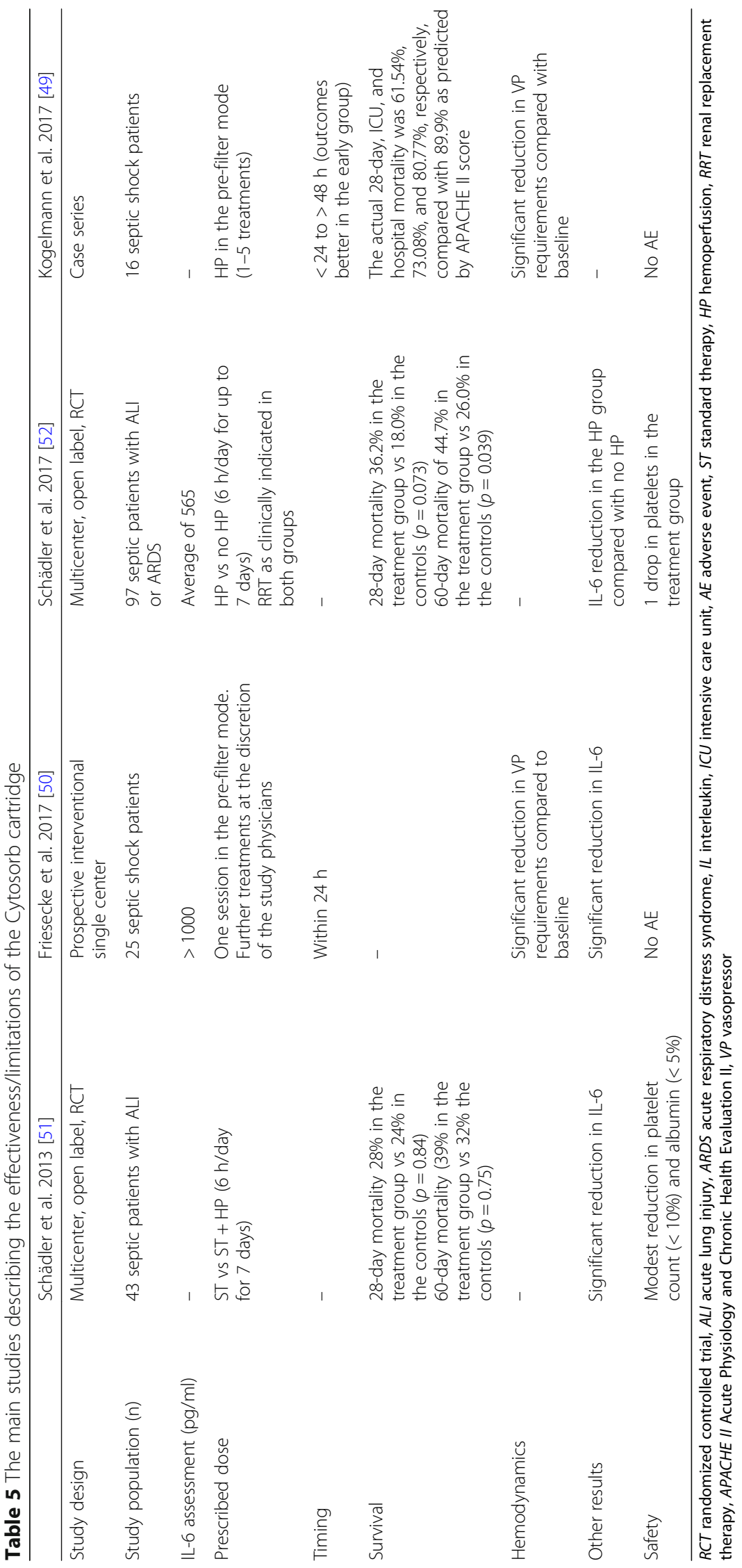


Table 6 The main studies describing the effectiveness/limitations of the HA 330 cartridge

\begin{tabular}{|c|c|c|}
\hline & Huang et al. 2010 [56] & Huang et al. 2013 [57] \\
\hline Study design & $\mathrm{RCT}$ & RCT \\
\hline Study population (n) & 44 sepsis or septic shock patients & 46 ALI/extra-pulmonary sepsis patients \\
\hline EAA assessment & - & - \\
\hline Prescribed dose & $\mathrm{HP}$ for $2 \mathrm{~h}$ for 3 days & $\mathrm{HP}$ for $2 \mathrm{~h}$ for 3 days \\
\hline Survival & $\begin{array}{l}\cdot \text { ICU mortality } 12.5 \% \text { in HA vs } \\
45.0 \% \text { in the controls }(p=0.02) \\
\cdot \text { Hospital mortality } 37.5 \% \text { in HA } \\
\text { vs } 50.0 \% \text { in the controls ( } p=0.81) \\
\cdot 28 \text {-day mortality } 45.8 \% \text { in HA vs } \\
55.0 \% \text { in controls }(p=0.47)\end{array}$ & $\begin{array}{l}\cdot \text { ICU mortality } 24 \% \text { in HA vs } 57.14 \% \text { in } \\
\text { the controls }(p=0.02) \\
\cdot 28 \text {-day mortality } 28 \% \text { in HA vs } 66.7 \% \text { in } \\
\text { the controls ( } p=0.009)\end{array}$ \\
\hline Length of ICU stay (days) & $\begin{array}{l}12.4 \pm 3.1 \text { in HA vs } 19.5 \pm 4.0 \text { in } \\
\text { controls }(p=0.03)\end{array}$ & $\begin{array}{l}15.5 \pm 4.0 \text { in HA vs } 19.4 \pm 3.1 \text { in } \\
\text { controls }(p=0.04)\end{array}$ \\
\hline Hemodynamics & $\begin{array}{l}\text { Significant reduction in VP dose in } \\
\text { the HA group vs increase in the } \\
\text { control group }(p=0.01)\end{array}$ & $\begin{array}{l}\text { Significant reduction in VP dose in the } \\
\text { HA group vs increase in the control } \\
\text { group }(p=0.032)\end{array}$ \\
\hline Other results & $\begin{array}{l}\text { Significant difference in IL-8 and } \\
\text { IL-6 levels between the two groups } \\
\text { at day } 3 \text { ( } p=0.03 \text { and } 0.01 \text {, respectively) }\end{array}$ & $\begin{array}{l}\text { Significant difference in IL-1 and TNF-a } \\
\text { in BAL fluid between the two groups } \\
(p=0.02 \text { and } 0.04 \text {, respectively) }\end{array}$ \\
\hline Safety & $\begin{array}{l}\text { - } 1 \text { patient with fever in the HA group } \\
\text { - Transient reduction in platelet counts in } \\
\text { the HP group }\end{array}$ & - \\
\hline
\end{tabular}

$R C T$ randomized controlled trial, $A L I$ acute lung injury, EAA endotoxin activity assay, $H A$ hemadsorption, $H P$ hemoperfusion, ICU intensive care unit, TNF tumor necrosis factor, BAL broncho-alveolar lavage, VP vasopressor, IL interleukin

terminated early due to difficulty recruiting patients (NCT02335723).

Hemoperfusion is a well-tolerated and feasible technique. There is no robust evidence for the use of HP in sepsis; however, some studies suggest a trend toward hemodynamic improvement and decreased mortality with its use.

\section{Coupled plasma filtration adsorption Terminology}

Coupled plasma filtration adsorption $\left(\mathrm{CPFA}^{\mathrm{m}}\right)$ is a combination of separation of plasma from the cellular components of blood with a highly permeable filter, followed by sorbent adsorption of the plasma component with a styrene resin to remove a number of different cytokines and then reinfusion of the purified plasma before the hemofilter to finally simultaneously provide CRRT for renal/fluid support. The advantage of CPFA is the lack of direct contact between blood cells with the sorbent material, which leads to improved biocompatibility.

A CPFA circuit is shown in Fig. 4.

\section{Technical aspects}

- Blood flow rate (Qb): typically, $150-220 \mathrm{ml} / \mathrm{min}$ (max $250 \mathrm{ml} / \mathrm{min}$ ).
- Plasma flow rate: $17-20 \%$ of the blood flow rate (35-40 $\mathrm{ml} / \mathrm{min})$.

- Ultrafiltration rate: $\max 2500 \mathrm{ml} / \mathrm{h}$ (equivalent to $35 \mathrm{ml} / \mathrm{kg} / \mathrm{h}$ in a $70 \mathrm{~kg}$ patient).

- Replacement fluid (Qr): usually in post-dilution mode.

- Duration: daily for five days lasting for at least $10 \mathrm{~h} /$ day.

- Anticoagulation: the typical anticoagulant used is heparin, but citrate has been used safely [63] and may represent an attractive alternative given the high rate of clotting with CPFA.

The effectiveness of CPFA is dose-dependent, and volumes of plasma cleared in excess of $0.18 \mathrm{~L} / \mathrm{kg} /$ day are typically associated with better outcomes [64].

\section{The evidence}

The evidence for the use of CPFA is largely derived from small, observational studies [65-68], which suggested no benefit in terms of survival or ICU-LOS but potential improvement in hemodynamics, interestingly, in a dosedependent fashion. A recent meta-analysis that involved 14 studies suggested a potential improvement in survival, but the studies were not high quality and had a small size [69]. The largest RCT to date is the COMPACT trial [64] involving 192 patients randomized to either standard of care versus CPFA plus standard of care. There was no difference in hospital mortality (controls 
Table 7 The main studies describing the effectiveness/limitations of LPS adsorbers

\begin{tabular}{|c|c|c|c|}
\hline & Yaroustovsky et al. 2009 [60] & Ala-Kokko et al. 2011 [61] & Adamik et al. 2015 [62] \\
\hline Study design & Observational & Case series with matched controls & Observational \\
\hline Study population (n) & 13 Gram-negative sepsis & $\begin{array}{l}24 \text { septic shock patients and } \\
\text { endotoxaemia. }\end{array}$ & $\begin{array}{l}62 \text { septic shock and suspected } \\
\text { Gram-negative }\end{array}$ \\
\hline EAA assessment & - & $\begin{array}{l}\text { More than } 0.3 \text { considered } \\
\text { endotoxaemia }\end{array}$ & EA [0.70 EA units $(0.66-0.77)]$ \\
\hline Prescribed dose & $\begin{array}{l}\text { Two sessions with a maximum } \\
\text { duration of } 120 \mathrm{~min} / \text { patient } \\
\text { Alteco adsorber }(n=6) \text { and } \\
\text { toraymyxin }(n=7)\end{array}$ & 2-h LPS HP & $\begin{array}{l}\text { LPS elimination + ST vs ST } \\
1-2 \text { sessions }\end{array}$ \\
\hline Timing & - & Within $36 \mathrm{~h}$ & Within $24 \mathrm{~h}$ \\
\hline Survival & - & - & No effect \\
\hline $\begin{array}{l}\text { Length of ICU } \\
\text { stay }\end{array}$ & - & - & No effect \\
\hline Hemodynamics & Improved MAP & Decreased VP & $\begin{array}{l}\text { Significant improvement in the } \\
\text { treatment group }\end{array}$ \\
\hline Other results & $\begin{array}{l}\text { Decrease in endotoxin } \\
\text { and procalcitonin levels }\end{array}$ & Decreased endotoxin levels & Decreased endotoxin levels \\
\hline Safety & & $\begin{array}{l}\text { Low platelets, two patients requiring } \\
\text { transfusion but no bleeding }\end{array}$ & \\
\hline
\end{tabular}

EAA endotoxin activity assay, ST standard therapy, MAP mean arterial pressure, VP vasopressors, LPS lipopolysaccharide, HP hemoperfusion

(47.3\%) vs CPFA (45.1\%); $p=0.76)$ or ICU-free days during the first 30 days ( 6.8 vs $7.5 ; p=0.35)$. The trial was stopped prematurely due to futility. COMPACT I [64] highlighted a few technical issues related to CPFA. First, nearly half of the patients in the CPFA arm did not reach the planned dose. Clotting of the circuit was the cause in $48 \%$ of cases despite the use of heparin. Second, cost was a major concern. The high cost contributed to under-treatment, as replacing the circuit when the treatment was interrupted due to clotting was not possible. Finally, CPFA requires adequate staff training because it is somewhat complex. Two other large RCTs

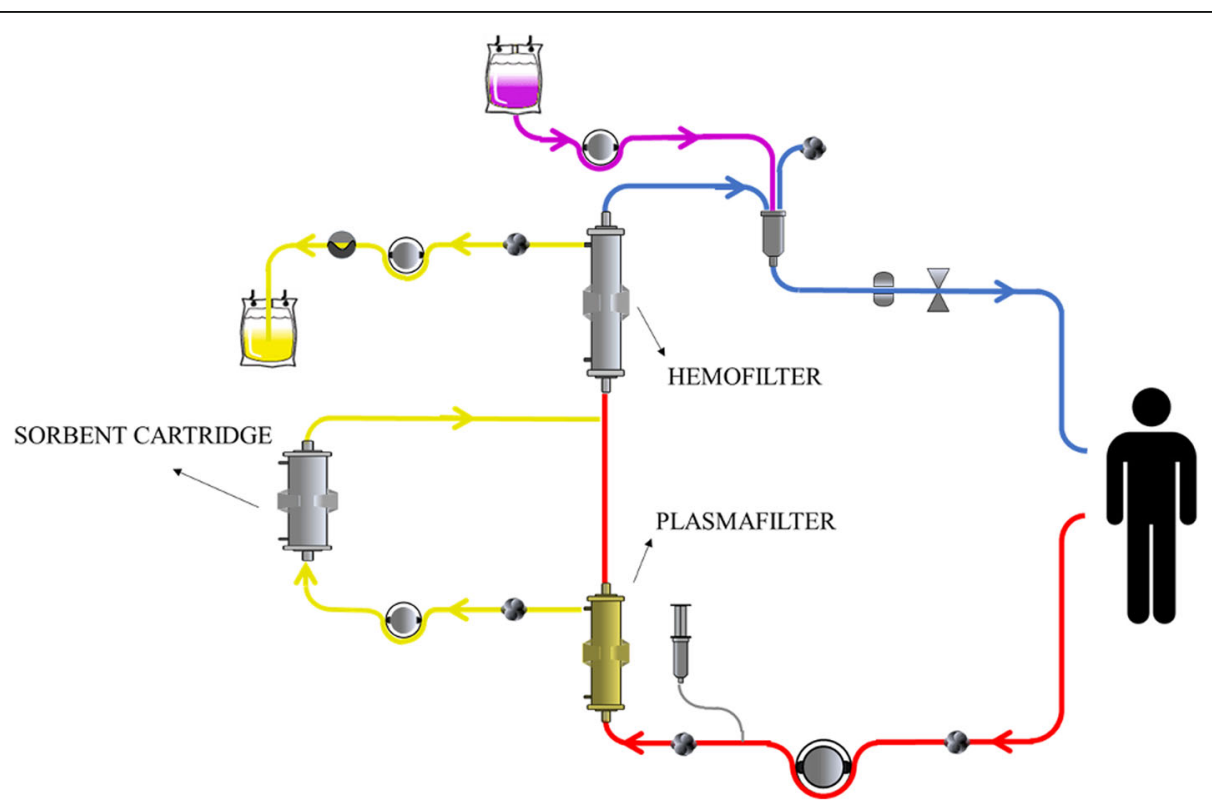

Fig. 4 Circuit components in coupled plasma filtration adsorption (CPFA). Arterial line (red), plasma (yellow, pre-hemofilter), ultrafiltrate (yellow, post-hemofilter), replacement fluid (purple), and venous line (blue) 
are ongoing (COMPACT II (NCT01639664) and ROMPA (NCT02357433)), which should help expand the body of evidence concerning the feasibility and effectiveness of CPFA.

CPFA is feasible but evidence supporting its effectiveness to date is limited. Furthermore, it is expensive, labor-intensive, and associated with multiple technical issues that often lead to under-treatment. Well organized staff training programs are required when considering the utilization of this technique.

\section{Adverse events (the pitfalls)}

It is important to recognize that the above-described techniques are not without side effects. Adverse events associated with their use should not be overlooked, but rather carefully monitored. In particular, in light of the current low level of evidence supporting the effectiveness of these techniques, their use should be highly individualized and only practiced in centers with adequate experience and capabilities for vigilant monitoring of patients. Common to all the techniques are extracorporeal circuit-related adverse events. The risks of bleeding, clotting/changes in anti-coagulation requirements, drops in platelets counts, and catheter complications are all well-known. Also common to all techniques is the important issue of drug removal. Antimicrobials, in particular, are of utmost importance [70-72]. In septic patients, antibiotics are the only proven therapy. The risk of antibiotic removal, or under-dosing of patients, should be carefully accounted for by accurate drug level monitoring. In an in vitro study examining the effect of adsorption (as an example) on drug removal [73], vancomycin, for instance, showed a significant reduction in levels at different time points following adsorption therapy. Additional antibiotics doses may often be required. An unpredictable loss of beneficial molecules such as albumin (particularly in the case of HCO membrane use), other nutrients, and amino acids is another important consideration. Electrolyte imbalances (hypophosphatemia and hypokalemia in particular) are other important issues that could be harmful, particularly in critically ill patients, and should be carefully monitored. The risk is more pronounced in HVHF use, as emphasized by Clark et al. [23]. Frequent monitoring and pre-prepared protocols for electrolyte replacement are important. Furthermore, all these techniques add some complexity to the usual RRT prescription. Adequate personnel training is required before these techniques can be applied. Finally, all these techniques share the disadvantage of high cost. The current level of evidence is not in favor of utilizing these techniques given the high cost. As far as technique-specific adverse events, adsorption is associated with thrombocytopenia and leukopenia (as highlighted in the above-described studies). HVHF places patients at risk of hemodynamic instability and hypothermia with high convection [74]. HVHF also results in an increased nursing workload (more frequent procedures, such as bag changes in particular), which can lead to the possible introduction of error. With regard to $\mathrm{HCO}$ use, albumin loss is particularly significant in comparison to other techniques. This can be minimized by applying CVVHD, as convective clearance is more associated with albumin loss compared with diffusive clearance, while increasing the effluent flow to increase cytokine clearance [27].

Adverse events, such as exposure to extracorporeal circuit, antibiotic removal, loss of beneficial molecules, electrolyte imbalances, increased cost, and increased work load, should be carefully monitored.

\section{Future directions}

The high morbidity and mortality associated with sepsis, along with the magnitude of health care resources utilized when managing septic patients, explain the ongoing efforts to optimize therapy. Therapeutic strategies aiming at elimination of the inflammatory mediators involved in the pathogenesis of sepsis represent an attractive and evolving area. As summarized in our review, different extracorporeal techniques have been studied, and the body of evidence to support their use is growing but remains controversial at this stage. With the current level of evidence, these techniques should not be widely adopted until the level of evidence to support their use is more robust.

In this section, we share our personal view on the use of extracorporeal therapies in sepsis. Across the different modalities, there has been a trend towards hemodynamic improvement. Its effect, however, in terms of decreasing mortality and length of ICU/hospital stay is, for the most part, limited and somewhat conflicting. Nevertheless, it is important to note that although mortality and length of ICU/hospital stay are important outcomes, they may not be the only desired outcomes in this setting. These techniques may potentially serve as a bridge to stabilize critically ill patients until more definitive therapies take place.

The application of these extracorporeal techniques is generally highly variable worldwide depending on resources and local expertise. Therapy should be tailored to the individual patient condition. Furthermore, side effects should be carefully monitored. In our opinion, the stage at which the patient is captured may influence the choice of modality. Earlier in the course, when levels of endotoxins and cytokines are extremely high, the application of adsorption/CPFA may help deactivate and decrease the 
peak elevation of these mediators, resulting in clinical outcomes. Later in the course, adsorption techniques may not be as effective, as the damage caused by the elevated mediators has already taken place, and utilization of the potential benefits of HCO membranes or HVHF for organ support may be more appropriate. Further studies are needed to confirm the theoretical effect of timing of the start of therapy on the utilized modality.

Another area in which future trials are still needed is adsorption. To date, the evidence to support its effectiveness is limited; however, in our opinion, there are important considerations before concluding that it is ineffective. Adsorption in particular seems to be dependent on the initial level (the higher the initial level of the desired solute for clearance, the more effective is the therapy, which may translate to clinical outcomes). This phenomenon has been demonstrated in the EUPRATES trial (NCT01046669), as benefit was observed in a subpopulation of patients with higher endotoxin levels. Treatment frequency also seems to have an effect (the more frequent the therapy, the more effective it becomes). This phenomenon has been demonstrated in studies utilizing adsorption in the treatment of poisoning, but the concept applies in other acute conditions [75]. Moreover, the range of molecular weights removed by adsorption is wider (in comparison to other techniques). Therefore, if applied early in the course during which the inflammatory mediator level is at its peak and continued sufficiently long, adsorption may represent a more promising tool in comparison to the other techniques. However, this hypothesis remains to be confirmed.

\section{Conclusions}

To date, evidence is insufficient to support the use of extracorporeal techniques in sepsis. However, further efforts to try to identify research gaps in an attempt to optimize their use in septic patients are warranted. Our review aims to provide a comprehensive overview concerning both the benefits and risks of these techniques. Further studies to guide clinicians in the application of these techniques in the proper clinical setting are still needed.

\footnotetext{
Abbreviations

AKI: Acute kidney injury; APACHE II: Acute Physiology and Chronic Health Evaluation II; Cl: Confidence interval; CPFA: Coupled plasma filtration adsorption; CRRT: Continuous renal replacement therapy; CS: Cytosorb; CWH: Continuous veno-venous hemofiltration; CWHDF: Continuous venovenous hemodiafiltration; DAMPs: Damage-associated molecular patterns; ESICM: European Society of Intensive Care Medicine; HCO: High cut-off; HCOCWHD: High cut-off continuous veno-venous hemodialysis; HCO-HD: Highcut-off hemodialysis; HR: Hazard ratio; HVHF: High volume hemofiltration; ICU: Intensive care unit; IL: Interleukin; KDIGO: Kidney Disease Improving Global Outcomes; Kuf: Ultrafiltration coefficient of the dialyzer; LOS: Length of stay; LPS: Lipopolysaccharide; OR: Odds ratio; PAMPs: Pathogen-associated molecular patterns; PHVHF: Pulse high volume hemofiltration; PMX: Polymyxin B-immobilized fiber column; Qb: Blood flow rate; Qr: Replacement fluid; qSOFA: Quick sequential organ failure assessment score; RCT: Randomized controlled trial; RR: Risk ratio; RRT: Renal replacement therapy; SCCM: Society of Critical Care Medicine; SIRS: Systemic inflammatory
}

response syndrome; SVHF: Standard volume hemofiltration; TNF: Tumour necrosis factor; VHVHF: Very high volume hemofiltration

\section{Authors' contributions}

GA carried out the literature review, manuscript drafting, editing, and reviewing, MN contributed to the manuscript editing, reviewing, and preparation of figures, JZ contributed to the literature review and manuscript drafting, $A B$ contributed to the literature review and manuscript drafting, ZR contributed to the manuscript reviewing and editing, and CR contributed to the manuscript reviewing and editing. All authors read and approved the final manuscript.

Ethics approval and consent to participate

Not applicable.

\section{Consent for publication \\ Not applicable.}

\section{Competing interests}

The authors declare that they have no competing interests.

\section{Publisher's Note}

Springer Nature remains neutral with regard to jurisdictional claims in published maps and institutional affiliations.

\section{Author details}

${ }^{1}$ Department of Internal Medicine and Nephrology, King Abdulaziz University, Jeddah, Saudi Arabia. ${ }^{2}$ International Renal Research Institute of Vicenza (IRRIV), Vicenza, Italy. ${ }^{3}$ Department of Nephrology, Dialysis and

Transplantation, San Bortolo Hospital, Vicenza, Italy. ${ }^{4}$ Department of Emergency and Critical Care Medicine, The Second Hospital of Jilin University, Changchun, China. ${ }^{5}$ Department of Internal Medicine, University of Trieste, Trieste, Italy. ${ }^{6}$ Department of Cardiology and Cardiac Surgery, Paediatric Cardiac Intensive Care Unit, Bambino Gesù Children's Hospital, IRCCS, Rome, Italy.

Received: 26 April 2018 Accepted: 10 September 2018

Published online: 25 October 2018

\section{References}

1. Singer M, Deutschman CS, Warren Seymour C, Shankar-Hari M, Annane D, Bauer $M$, et al. The Third International Consensus Definitions for Sepsis and Septic Shock. J Am Med Assoc. 2016;315(8):801-10.

2. Shankar-Hari M, Phillips G, Levy M, Seymour C, Liu V, Deutschman C, et al. Developing a new definition and assessing new clinical criteria for septic shock: for the Third International Consensus Definitions for Sepsis and Septic Shock (Sepsis-3). JAMA. 2016:315(8):775-87.

3. Suffredini AF, Fromm RE, Parker MM, Brenner M, Kovacs JA, Wesley RA, Parrillo JE. The cardiovascular response of normal humans to the administration of endotoxin. N Engl J Med. 1989;321(5):280

4. Hoffman WD, Natanson C. Endotoxin in septic shock. Anesth Analg. 1993;77: 613-24.

5. Rhodes A, Evans LE, Alhazzani W, Levy MM, Antonelli M, Ferrer R, et al. Surviving Sepsis Campaign: International Guidelines for Management of Sepsis and Septic Shock: 2016. Intensive Care Med. 2017:43(3):304-77.

6. Kellum JA, Angus DC, Johnson JP, Leblanc M, Griffin M, Ramakrishnan N, et al. Continuous versus intermittent renal replacement therapy: a metaanalysis. Intensive Care Med. 2002;28(1):29-37.

7. De Vriese AS, Colardyn FA, Philippé JJ, Vanholder RC, De Sutter JH, Lameire $\mathrm{NH}$. Cytokine removal during continuous hemofiltration in septic patients. J Am Soc Nephrol. 1999;10(4):846-53.

8. Villa G, Neri M, Bellomo R, Cerda J, De Gaudio AR, De Rosa S, et al. Nomenclature for renal replacement therapy and blood purification techniques in critically ill patients: practical applications. Crit Care. 2016; 20(1):283.

9. VA/NIH Acute Renal Failure Trial Network, Palevsky PM, Zhang JH, O'Connor TZ, Chertow GM, Crowley ST, Choudhury D, Finkel K, Kellum JA, Paganini E, Schein RM, Smith MW, Swanson KM, Thompson BT, Vijayan A, Watnick S, Star RA, Peduzzi P. Intensity of renal support in critically ill patients with acute kidney injury. N Engl J Med. 2008;359(1):7-20.

10. O'Brien Z, Cass A, Cole L, Finfer S, Gallagher M, McArthur C, McGuiness S, Myburgh J, Bellomo R, MJRSI and the A and NZICCTG. Intensity of 
continuous renal-replacement therapy in critically ill patients. N Engl J Med. 2009:361(17):1627-38.

11. Saudan P, Niederberger M, De Seigneux S, Romand J, Pugin J, Perneger T, et al. Adding a dialysis dose to continuous hemofiltration increases survival in patients with acute renal failure. Kidney Int. 2006;70(7):1312-7.

12. Joannes-Boyau O, Rapaport S, Bazin R, Fleureau C, Janvier G. Impact of high volume hemofiltration on hemodynamic disturbance and outcome during septic shock. ASAIO J. 2004;50(1):102-9.

13. Piccinni P, Dan M, Barbacini S, Carraro R, Lieta E, Marafon S, et al. Early isovolaemic haemofiltration in oliguric patients with septic shock. Intensive Care Med. 2006;32(1):80-6

14. Cornejo R, Downey P, Castro R, Romero C, Regueira T, Vega J, et al. Highvolume hemofiltration as salvage therapy in severe hyperdynamic septic shock. Intensive Care Med. 2006;32(5):713-22.

15. Cole L, Bellomo R, Journois D, Davenport P, Baldwin I, Tipping P. High-volume haemofiltration in human septic shock. Intensive Care Med. 2001;27(6):978-86.

16. Boussekey N, Chiche A, Faure K, Devos P, Guery B, d'Escrivan T, et al. A pilot randomized study comparing high and low volume hemofiltration on vasopressor use in septic shock. Intensive Care Med. 2008;34:1646-53.

17. Joannes-Boyau O, Honoré PM, Perez P, Bagshaw SM, Grand H, Canivet IL, et al. High-volume versus standard-volume haemofiltration for septic shock patients with acute kidney injury (IVOIRE study): A multicentre randomized controlled trial. Intensive Care Med. 2013;39(9):1535-46.

18. Honore PM, Jamez J, Wauthier M, Lee PA, Dugernier T, Pirenne B, et al. Prospective evaluation of short-term, high-volume isovolemic hemofiltration on the hemodynamic course and outcome in patients with intractable circulatory failure resulting from septic shock. Crit Care Med. 2000;28(11):3581-7.

19. Ratanarat R, Brendolan A, Piccinni P, Dan M, Salvatori G, Ricci Z, et al. Pulse high-volume haemofiltration for treatment of severe sepsis: effects on hemodynamics and survival. Crit Care. 2005;9(4):R294-302.

20. Peng Z, Pai P, Han-Min W, Jun Z, Hong-Bao L, Rong L, et al. Evaluation of the effects of pulse high-volume hemofiltration in patients with severe sepsis: a preliminary study. Int J Artif Organs. 2010;33(8):505-11.

21. Zhang $P$, Yang $Y, L v R$, Zhang $Y$, Xie W, Chen J. Effect of the intensity of continuous renal replacement therapy in patients with sepsis and acute kidney injury: a single-center randomized clinical trial. Nephrol Dial Transplant. 2012;27(3):967-73.

22. Borthwick EMJ, Hill CJ, Rabindranath KS, Maxwell AP, McAuley DF, Blackwood B. High-volume haemofiltration for sepsis in adults. Cochrane Database of Systematic Reviews 2017, Issue 1. Art. No.CD008075. https://doi. org/10.1002/14651858.CD008075.pub3.

23. Clark E, Molnar AO, Joannes-Boyau O, Honoré PM, Sikora L, Bagshaw SM High-volume hemofiltration for septic acute kidney injury: a systematic review and meta-analysis. Crit Care. 2014;18(1):1-9.

24. Lehner GF, Wiedermann CJ, Joannidis M. High-volume hemofiltration in critically ill patients: a systematic review and meta-analysis. Minerva Anestesiol. 2014;80(5):595-609.

25. Chung KK, Coates EC, Smith DJ, Karlnoski RA, Hickerson WL, Arnold-Ross AL, et al. High-volume hemofiltration in adult burn patients with septic shock and acute kidney injury: a multicenter randomized controlled trial. Crit Care. 2017:21(1):4-11.

26. Kidney Disease: Improving Global Outcomes Work Group. Kidney Disease: Improving GLobal Outcomes (KDIGO) clinical practice guideline for acute kidney injury. Kidney Int Suppl. 2012;2:1-138.

27. Morgera S, Slowinski T, Melzer C, Sobottke V, Vargas-Hein O, Volk T, et al. Renal replacement therapy with high-cutoff hemofilters: impact of convection and diffusion on cytokine clearances and protein status. Am J Kidney Dis. 2004;43(3):444-53.

28. Morgera S, Rocktaschel J, Haase M, Lehmann C, von Heymann C, Ziemer S, et al. Intermittent high permeability hemofiltration in septic patients with acute renal failure. Intensive Care Med. 2003;29(11):1989-95.

29. Morgera S, Haase M, Rocktäschel J, Böhler T, Vargas-Hein O, Melzer C, et al. Intermittent high-permeability hemofiltration modulates inflammatory response in septic patients with multiorgan failure. Nephron Clin Pract. 2003;94(3): $: 75-80$

30. Morgera S, Haase M, Kuss T, Vargas-Hein O, Zuckermann-Becker H, Melzer C, Krieg H, Wegner B, Bellomo R, Neumayer H-H. Pilot study on the effects of high cutoff hemofiltration on the need for norepinephrine in septic patients with acute renal failure. Crit Care Med. 2006;34(8):2099-246.

31. Haase M, Bellomo R, Baldwin I, Haase-Fielitz A, Fealy N, Davenport P, et al. Hemodialysis membrane with a high-molecular-weight cutoff and cytokine levels in sepsis complicated by acute renal failure: a phase 1 randomized trial. Am J Kidney Dis. 2007;50(2):296-304.

32. Chelazzi C, Villa G, D'Alfonso MG, Mancinelli P, Consales G, Berardi M, et al. Hemodialysis with high cut-off hemodialyzers in patients with multi-drug resistant Gram-negative sepsis and acute kidney injury: a retrospective, casecontrol study. Blood Purif. 2016;42(3):186-93.

33. Villa G, Chelazzi C, Morettini E, Zamidei L, Valente S, Caldini AL, et al. Organ dysfunction during continuous veno-venous high cut-off hemodialysis in patients with septic acute kidney injury: A prospective observational study. PLoS ONE. 2017;12(2):e0172039. https://doi.org/10.1371/journal.pone. 0172039.

34. Kade G, Lubas A, Rzeszotarska A, Korsak J, Niemczyk S. Effectiveness of high cut-off hemofilters in the removal of selected cytokines in patients during septic shock accompanied by acute kidney injurypreliminary study. Med Sci Monit. 2016;22:4338-44.

35. Honore PM, Clark W. Novel therapeutical concepts for extracorporeal treatment of hyperinflammation and sepsis: immunomodulation. approach with a novel high Cut-OFF membrane: the SepteX membrane. In Proceedings of 10th Congress of World Federation of CCU (WFSICCM) 2009. Florence.

36. Villa G, Zaragoza JJ, Sharma A, Neri M, De Gaudio AR, Ronco C. Cytokine removal with high cut-off membrane: Review of literature. Blood Purif. 2014; 38(3-4):167-73.

37. Vincent IL, Laterre PF, Cohen J, Burchardi $H$, Bruining $H$, Lerma FA, Wittebole X, de Backer D, Drett S, Marzo D, Nakamura H, John S. A pilot controlled study of a polymixin b-immobilized hemoperfusion cartidge in patients with severe sepsis secondary to intra-abdominal infection. Shock. 2005;23(5):400-5.

38. Cruz DN, Antonelli M, Fumagalli R, Foltran F, Brienza N, Donati A, Malcangi V, Petrini F, Volta G, Bobbio Pallavicini FM, Rottoli F, Giunta F, Ronco C. Early use of polymyxin B hemoperfusion in abdominal septic shock: the EUPHAS randomized controlled trial. JAMA. 2009;301(23):2445.

39. Payen DM, Guilhot J, Launey Y, Lukaszewicz AC, Kaaki M, Veber B, et al. Early use of polymyxin B hemoperfusion in patients with septic shock due to peritonitis: a multicenter randomized control trial. Intensive Care Med. 2015; 41:975-84.

40. Iwagami M, Yasunaga $H$, Noiri E, Horiguchi H, Fushimi K, Matsubara T, Yahagi N, Nangaku M, Doi K. Potential survival benefit of polymyxin B hemoperfusion in septic shock patients on continuous renal replacement therapy: a propensity-matched analysis. Blood Purif. 2016;42(1):9-17.

41. Iwagami M, Yasunaga H, Doi K, Horiguchi H, Fushimi K, Matsubara T, et al. Postoperative polymyxin B hemoperfusion and mortality in patients with abdominal septic shock: a propensity-matched analysis. Crit Care Med. 2014; 42:1187-93

42. Cutuli SL, Artigas A, Fumagalli R, Monti G, Ranieri VM, Ronco C, Antonelli M, EUPHAS 2 Collaborative Group. Polymyxin-B hemoperfusion in septic patients: analysis of a multicenter registry. Ann Intensive Care. 2016:6(1):77.

43. Terayama T, Yamakawa K, Umemura Y, Aihara M, Fujimi S. Polymyxin B hemoperfusion for sepsis and septic shock: a systematic review and metaanalysis. Surg Infect. 2017;18(3):225-33.

44. Cruz DN, Perazella MA, Bellomo R, et al. Effectiveness of polymyxin Bimmobilized fiber column in sepsis: a systematic review. Crit Care. 2007;11(2):R47.

45. Qiu XH, Liu SQ, Guo FM, Yang Y, Qiu HB. A meta-analysis of the effects of direct hemoperfusion with polymyxin B-immobilized fiber on prognosis in severe sepsis. Zhonghua Nei Ke Za Zhi. 2011;50(4):316-21.

46. Zhou F, Peng Z, Murugan R, Kellum JA. Blood purification and mortality in sepsis: a meta-analysis of randomized trials. Crit Care Med. 2013;41(9):2209-20.

47. Kellum JA, Venkataraman R, Powner D, Elder M, Hergenroeder G, Carter M. Feasibility study of cytokine removal by hemoadsorption in brain-dead humans. Crit Care Med. 2008;36(1):268-72.

48. Iba T, Fowler L. Is polymyxin B-immobilized fiber column ineffective for septic shock? A discussion on the press release for EUPHRATES trial. Journal of Intensive Care. 2017;5:40. https://doi.org/10.1186/s40560-017-0236-x.

49. Kogelmann $\mathrm{K}$, Jarczak D, Scheller M, Drüner M. Hemoadsorption by CytoSorb in septic patients: a case series. Crit Care. 2017;21(1):1-10.

50. Friesecke S, Stecher SS, Gross S, Felix SB, Nierhaus A. Extracorporeal cytokine elimination as rescue therapy in refractory septic shock: a prospective single-center study. J Artif Organs. 2017;20(3):252-9.

51. Schädler D, Porzelius C, Jörres A, Marx G, Meier-Hellmann A, Putensen C, et al. A multicenter randomized controlled study of an extracorporeal cytokine hemoadsorption device in septic patients. Crit Care. 2013;17(Suppl 2):P62. 
52. Schädler D, Pausch C, Heise D, Meier-Hellmann A, Brederlau J, Weiler N, et al. The effect of a novel extracorporeal cytokine hemoadsorption device on IL-6 elimination in septic patients: a randomized controlled trial. PLoS One. 2017;12(10):e018701.

53. Friesecke S, Träger K, Schittek GA, Molnar Z, Bach F, Kogelmann K, Bogdanski R, Weyland A, Nierhaus A, Nestler F, Olboeter D. International registry on the use of the CytoSorb ${ }^{\circledR}$ adsorber in ICU patients. Medizinische Klinik-Intensivmedizin und Notfallmedizin. 2017. p. 1-9.

54. Gruda MC, Ruggeberg KG, O'Sullivan P, Guliashvili T, Scheirer AR, Golobish TD, Capponi VJ, Chan PP. Broad adsorption of sepsis-related PAMP and DAMP molecules, mycotoxins, and cytokines from whole blood using CytoSorb sorbent porous polymer beads. PloS one. 2018;13(1):e0191676.

55. Bernardi MH, Rinoesl H, Dragosits K, Ristl R, Hoffelner F, Opfermann P, et al. Effect of hemoadsorption during cardiopulmonary bypass surgery - a blinded, randomized, controlled pilot study using a novel adsorbent. Crit Care. 2016;20:96. https://doi.org/10.1186/s13054-016-1270-0.

56. Huang Z, Wang SR, Su W, Liu JY. Removal of humoral mediators and the effect on the survival of septic patients by hemoperfusion with neutral microporous resin column. Ther Apher Dial. 2010;14(6):596-602.

57. Huang Z, Wang SR, Yang ZL, Liu JY. Effect on extrapulmonary sepsisinduced acute lung injury by hemoperfusion with neutral microporous resin column. Ther Apher Dial. 2013;17(4):454-61.

58. Turani F, Candidi F, Barchetta R, Grilli E, Belli A, Papi E, et al. Continuous renal replacement therapy with the adsorbent membrane oXiris in septic patients: A clinical experience. Crit Care. 2013;17:S22-3.

59. Shum HP, Chan KC, Kwan MC, Yan WW. Application of endotoxin and cytokine adsorption haemofilter in septic acute kidney injury due to Gramnegative bacterial infection. Hong Kong Med J. 2013;19(6):491-7.

60. Yaroustovsky M, Abramyan M, Popok Z, Nazarova E, Stupchenko O, Popov $D$, et al. Preliminary report regarding the use of selective sorbents in complex cardiac surgery patients with extensive sepsis and prolonged intensive care stay. Blood Purif. 2009;28(3):227-33.

61. Ala-Kokko TI, Laurila J, Koskenkari J. A new endotoxin adsorber in septic shock: Observational case series. Blood Purif. 2011;32(4):303-9.

62. Adamik B, Zielinski S, Smiechowicz J, Kübler A. Endotoxin elimination in patients with septic shock: an observation study. Arch Immunol Ther Exp. 2015;63(6):475-83.

63. Mariano F, Tetta C, Stella M, Biolino P, Miletto A, Triolo G. Regional citrate anticoagulation in critically III patients treated with plasma filtration and adsorption. Blood Purif. 2004;22(3):313-9.

64. Livigni S, Bertolini G, Rossi C, Ferrari F, Giardino M, Pozzato M, et al. Efficacy of coupled plasma filtration adsorption (CPFA) in patients with septic shock: a multicenter randomised controlled clinical trial. BMJ Open. 2014;4(1):e003536.

65. Hassan J, Abdul Cader R, Kong NCT, Mohd M, Raha Rahman A, Hod R. Coupled plasma filtration adsorption (CPFA) plus Continuous Veno-Venous Haemofiltration $(\mathrm{CWH})$ versus $\mathrm{CWH}$ alone as an adjunctive therapy in the treatment of sepsis. EXCLI J. 2013;12:681-92.

66. Cader RA, Gafor HA, Mohd R, Kong WY, Arshad N, Kong N. Coupled plasma filtration and adsorption (CPFA): a single center experience. Nephrourol Mon. 2013;5(4):891-6.

67. Formica M, Olivieri C, Livigni S, Cesano G, Vallero A, Maio M, Tetta C. Hemodynamic response to coupled plasmafiltration-adsorption in human septic shock. Intensive Care Med. 29(5):703-8.

68. Berlot G, Agbedjro A, Tomasini A, Bianco F, Gerini U, Viviani M, Giudici F. Effects of the volume of processed plasma on the outcome, arterial pressure and blood procalcitonin levels in patients with severe sepsis and septic shock treated with coupled plasma filtration and adsorption. Blood Purif. 2014;37(2):146-51.

69. Hazzard I, Jones S, Quinn T. Coupled plasma haemofiltration filtration in severe sepsis: Systematic review and meta-analysis. J R Army Med Corps. 2015;161(161):i17-22

70. Roberts D, Roberts J, Roberts M, Liu X, Nair P, Cole L, et al. Variability of antibiotic concentrations in critically ill patients receiving continuous renal replacement therapy: a multicentre pharmacokinetic study. Crit Care Med. 2012;40(5):1523-8.

71. Shimokawa K, Takakuwa R, Taya K, Wada Y, Yamazaki N, Murata M, Hirata K, Masuno T, Yokota H, Ishii F. Adsorption of various antimicrobial agents to endotoxin removal polymyxin-B immobilized fiber (Toraymyxin ${ }^{\oplus}$ ). Colloids Surf B: Biointerfaces. 2012;1(90):58-61.
72. Page M, Cohen S, Ber CE, Allaouchiche B, Kellum JA, Rimmelé T. In vivo antibiotic removal during coupled plasma filtration adsorption: A retrospective study. ASAIO J. 2014;60(1):70-5.

73. Reiter K, Bordoni V, Dall'Olio G, Ricatti MG, Soli M, Ruperti S, et al. In vitro removal of therapeutic drugs with a novel adsorbent system. Blood Purif. 2002;20(4):380-8.

74. Rokyta R, Matejovic M, Krouzecky A, Opatrny K, Ruzicka J, Novak I. Effects of continuous venovenous haemofiltration- induced cooling on global haemodynamics, splanchnic oxy gen and energy balance in critically ill patients. Nephrol Dial Transplant. 2004;19(3):623-30.

75. Shi Y, Bai Y, Zou Y, Cai B, Liu F, Fu P, et al. The value of plasma paraquat concentration in predicting therapeutic effects of haemoperfusion in patients with acute paraquat poisoning. PLoS One. 2012;7(7):e40911. 